\title{
CRESCIMENTO E DESENVOLVIMENTO DE FRUTOS DE CUPUAÇUZEIROS EM SISTEMA AGROFLORESTAL NO ESTADO DE RORAIMA, BRASIL ${ }^{1}$
}

\author{
GROWTH AND DEVELOPMENT OF CUPUAÇUZEIROS FRUITS IN \\ AGROFLORESTAL SYSTEMS IN THE STATE OF RORAIMA, BRAZIL ${ }^{1}$
}

\author{
Pedro Vitor Pereira Guimarães ${ }^{2}$ \\ Maria Fernanda Berlingieri Durigan ${ }^{3}$
}

RESUMO: O aumento da introdução de cupuaçuzeiros [Theobroma grandiflorum (Willd. ex Spreng.) K.Schum.] em sistemas de cultivos em Roraima evidencia a necessidade de estudos sobre a fenologia, crescimento e desenvolvimento de seus frutos nas condições do Estado, uma vez que registros técnico-científicos sobre esta cultura em sistema agroflorestais são escassos na região. Deste modo, objetivou-se caracterizar o crescimento e desenvolvimento de frutos de cupuaçuzeiros cultivados em um sistema agroflorestal no município de Cantá, Roraima. O delineamento experimental utilizado foi inteiramente casualizado, com número de repetições diferentes, totalizando 652 frutos avaliados. O experimento foi conduzido durante a safra 2016/17, entre os meses de outubro de 2016 e abril de 2017, instalado no Campo Experimental Confiança da Embrapa Roraima, a 90 km de Boa Vista, Roraima. Em condições de campo, avaliou-se o número de frutos total, o de botões florais, de flores e/ou resquícios florais, o diâmetro polar e o equatorial do fruto, a porcentagem de frutos viáveis, deformados e/ou mumificados, com presença de insetos, com presença de fungo e de frutos rachados. O período de desenvolvimento do cupuaçu compreendeu 180 dias e foi considerado a partir da abertura da flor (antese) até a abscisão do fruto. A floração e a frutificação inicial do cupuaçu em Cantá, Roraima ocorreram em época de seca, nos meses de outubro e novembro, respectivamente. Os diâmetros polar e equatorial dos frutos apresentaram crescimento que se ajustaram ao modelo sigmoidal simples. Os frutos com maturidade fisiológica apresentaram formatos do tipo oblongo, elíptico e ovoide, com constrição basal variando de ligeiro a forte e ápice variando de agudo a redondo.

1 Parte da dissertação de mestrado em Agroecologia do primeiro autor, financiada pela Coordenação de Aperfeiçoamento de Pessoal de Nível Superior e pela Petrobras (Projeto Cupuaçu Forte/n ${ }^{\circ}$

5850.0102917.16.2).

2 Doutorando em Biodiversidade e Biotecnologia da Rede de Biodiversidade e Biotecnologia da Amazônia Legal da Universidade Federal de Roraima. pedrovpg@hotmail.com

3 Doutora em Agronomia (Produção Vegetal), Orientadora, Pesquisadora da Empresa Brasileira de Pesquisa Agropecuária (Embrapa Roraima). maria.durigan@embrapa.br 
Palavras-chave: Theobroma grandiflorum (Willd. ex Spreng.) K.Schum.; Eventos fenológicos; Crescimento Vegetal; Maturação fisiológica.

\begin{abstract}
The increase in the introduction of cupuaçuzeiros [Theobroma grandiflorum (Willd. ex Spreng.) K.Schum.] in cropping systems in Roraima evidences the necessity of studies about the phenology, growth and development of its fruits under conditions of the state, since technical-scientific records on this crop in agroforestry systems are scarce in the region. In this way, this paper aimed to characterize the growth and development of cupuaçu fruits grown in an agroforestry system in Cantá, Roraima. Experimental design used was entirely randomized, with different number of repetitions, totaling 652 evaluated fruits. The experiment was conducted during the 2016/17 harvest, between October 2016 and April 2017, and installed in the Experimental Field of Embrapa Roraima, $90 \mathrm{~km}$ from Boa Vista, Roraima. On field conditions, were evaluated the number of fruits, floral buds, flowers and/or floral remnants, the polar and equatorial diameter of the fruit, the percentage of viable, deformed and/or mummified fruits, with presence of insects, with presence of fungus and cracked fruits. The period of development of cupuaçu comprised 180 days and it was considered from the opening of the flower (anthesis) to the abscission of the fruit. Flowering and initial fruiting in Cantá, Roraima, occured during the dry season, in October and November, respectively. The polar and equatorial diameters of the fruits presented growth that had adapted to the simple sigmoidal model. The fruits with physiological maturity presented oblong, elliptic and ovoid forms, with basal constriction varying from slight to strong and apex ranging from pointed to spherical.
\end{abstract}

Keywords: Theobroma grandiflorum (Willd. ex Spreng.) K.Schum.; Phenological events; Plant growth; Physiological maturation.

\title{
INTRODUÇÃO
}

O Brasil é considerado o primeiro no mundo em megadiversidade, tanto em número de espécies quanto em níveis de endemismo (Albagli, 2001), apontando uma enorme possibilidade de uso sustentável dos recursos naturais. A fruticultura brasileira tem enorme potencial para expandir sua participação no mercado internacional, ora mantendo o desempenho das exportações das principais frutas frescas comercializadas, ora na divulgação de outras frutas exóticas no mercado internacional ou na busca pela diversificação das exportações de frutas na forma processada (Bueno; Baccarin, 2012). 
De acordo com Souza et al. (2011) o cupuaçuzeiro [Theobroma grandiflorum (Willd. ex Spreng.) K.Schum.] é um dos recursos genéticos de fruteiras nativas mais importantes da região Amazônica, tanto do ponto de vista econômico, como social, cujo é destaque como fonte de renda e mão de obra para produtores rurais, especialmente, para agricultura familiar, indígena e pequenos produtores. Os frutos podem ser utilizados como matéria-prima para o desenvolvimento de produtos, como sorvetes, licores, compotas, geleias e biscoitos (Souza et al., 1999; Yang et al., 2003). Em comparação com a manteiga de cacau (Theobroma cacao L.), o óleo das sementes de cupuaçu apresenta ácidos graxos semelhantes, contém propriedades antioxidantes, é fonte importante dos ácidos graxos oleico, araquidônico e linoleico e também possui propriedades que permitem sua utilização industrial em alimentos e cosméticos (Alviárez et al., 2016).

O cupuaçuzeiro, por ser uma espécie típica de subdossel (Acevedo; Cruz; Herrera, 2009), com ampla adaptabilidade, pode ser facilmente consorciada com outras culturas de interesse econômico. Maciel; Assis; Yokomizo (2015) estudando arranjos agroflorestais no contexto da Agroecologia em Mazagão, Amapá, verificaram que os agricultores da região desenvolveram estratégias que têm possibilitado sua permanência em suas propriedades. Usam sistemas produtivos diversificados o que garante produção ao longo do ano. $\mathrm{O}$ açaizeiro (Euterpe oleracea Mart.), o cupuaçuzeiro e a bacabeira (Oenocarpus bacaba Mart.) são as espécies vegetais que apresentaram maior frequência na composição dos sistemas pesquisados, especialmente, em áreas mais úmidas, pela possibilidade de maior fonte de renda para a agricultura familiar local.

No entanto, por ser um fruto não climatério, a colheita do cupuaçu deve ser realizada quando ele alcança o máximo desenvolvimento e crescimento de todas as suas estruturas, em especial, a semente (embrião), que deve estar apta para sua reprodução ou em maturidade fisiológica (Acevedo; Cruz; Herrera, 2009). O desenvolvimento vegetal compreende os processos de crescimento, morfogênese e diferenciação. O crescimento, um aumento irreversível em tamanho, é efetivado principalmente pela expansão e divisão das células. A morfogênese é a aquisição de uma forma particular e a diferenciação é o 
processo pelo qual as células geneticamente idênticas tornam-se diferentes umas das outras por meio da expressão gênica diferencial (Raven; Evert; Eichhorn, 2014).

Para Hernández et al. (2006) o crescimento potencial dos frutos de cupuaçu está claramente determinado por fatores genéticos, pois, o componente varietal tem grande influência sobre a velocidade de crescimento e o tamanho final do fruto de cupuçuazeiro. Quando fisiologicamente maduro, o fruto de cupuaçu em ponto ótimo de colheita exala cheiro bastante agradável, e por ação de fitohormônios desprende-se da planta e cai no solo (Gondim et al., 2001; Souza et al., 2011), estando exposto a microrganismos, insetospragas, animais maiores e condições ambientais.

Desta forma, conhecer o ponto ótimo de colheita é essencial, pois, quando os frutos são colhidos fisiologicamente imaturos, não amadurecem, enrugam e apresentam exsudação da seiva, e se o amadurecimento ocorre, a qualidade dos frutos estará prejudicada (Hulme, 1970), depreciando o consumo e a comercialização de seus produtos. Na cultura do cupuaçu, recomenda-se fazer a coleta dos frutos diariamente, e mais de uma vez ao dia, em época de frutificação. O fruto maturo, não deve permanecer em contato com o solo por muito tempo (acima de 48 horas), pois, haverá redução de sua umidade, da massa e das características organolépticas desejáveis, prejudicando sua comercialização (Souza et al., 2011).

Neste sentido, estudos de fenologia, crescimento e desenvolvimento vegetal são úteis para tomadas de decisão, pois, podem ser utilizados no gerenciamento de colheitas, tratos culturais, aquisição de mão de obra e/ou maquinário. Ressalta-se que este tipo de estudo é importante em casos de surto de praga e/ou patógeno, no sentindo de se saber qual o momento fisiológico da espécie cultivada (vegetativo ou reprodutivo), e em qual estádio fisiológico encontram-se os frutos. No entanto, há poucos relatos na literatura relacionados ao crescimento e desenvolvimento dos frutos de cupuaçuzeiros, bem como, sobre os eventos fenológicos.

O aumento da introdução do cupuaçu nos sistemas de cultivo, em Roraima, torna evidente a necessidade de estudos sobre a fenologia, crescimento e desenvolvimento dos 
frutos nas condições do Estado, uma vez que, os registros técnico-científicos sobre esta cultura são escassos na região. Buscando caracterizar o crescimento e desenvolvimento de frutos de cupuaçu cultivados em sistema agroflorestal no município de Cantá, Roraima, estabeleceu-se este trabalho.

\section{MATERIAL E MÉTODOS}

O experimento foi conduzido durante a safra 2016/17, entre os meses de outubro de 2016 e abril de 2017, no Campo Experimental Confiança da Embrapa Roraima (coordenadas geográficas $02^{\circ} 15^{\prime} 00^{\prime \prime} \mathrm{N}, 60^{\circ} 39^{\prime} 54^{\prime \prime} \mathrm{W}$ e $100 \mathrm{~m}$ ), localizado no município de Cantá, na região central do Estado de Roraima, a 90 km de Boa Vista, Roraima, Brasil. A área estudada tinha consórcio de cupuaçu com abiu [Micropholis venulosa (Mart. \& Eichler ex Miq.) Pierre], andiroba (Carapa guyanensis Oliv.), café (Coffea canephora Pierre ex A.Froehner), castanha-da-Amazônia (Bertholletia excelsa Bonpl.), cupiúba (Goupia glabra Aubl.), gliricídia [Gliricidia sepium (Jacq.) Walp.], pupunha (Bactris gasipaes Kunth) e saman [Samanea saman (Jacq.) Merr.].

A região apresenta vegetação de floresta e clima do tipo Ami (Koppen), quente e semiúmido, com duas estações bem distintas: verão e inverno (Mourão Junior et al., 2003). A precipitação anual varia de 1795 a 2385 mm, com período chuvoso concentrado nos meses de maio a julho, que corresponde a mais de 55\% do total de precipitação (Ferreira; Tonini, 2009). O solo do sistema agroflorestal em que estudo foi desenvolvido, foi classificado como sendo Argissolo Vermelho-Amarelo, de textura argilosa (Mourão Junior et al., 2003).

De acordo com Corrêa (2005) na área a experiência com sistemas agroflorestais iniciou-se em 1995. O preparo do solo consistiu no desmatamento de capoeira de aproximadamente três anos, seguida da queima da vegetação. Utilizou-se o sistema agrossilvicultural sob condição de presença de insumos minerais. Ferreira; Tonini (2009) afirmam que o desenho espacial do sistema agroflorestal é do tipo multiestratificado, as parcelas medem $48 \mathrm{~m} \times 48 \mathrm{~m}$ e o espaçamento entre espécies é de $2 \mathrm{~m} \times 3 \mathrm{~m}$, com área útil abrangendo $192 \mathrm{~m}^{2}$, contendo 4 plantas de abiu (208 plantas ha ${ }^{-1}$ ), 2 plantas de andiroba 
(104 plantas ha-1), 6 plantas de café (312 plantas ha-1), uma castanha-da-Amazônia (56 plantas ha $\mathrm{ha}^{-1}$ ), uma cupiúba (52 plantas ha-1), 8 cupuaçuzeiros (416 plantas ha-1), 6 pupunheiras (338 plantas ha-1) e 4 plantas de saman (208 plantas ha' ${ }^{-1}$ ), sendo a bordadura composta por plantas de gliricídia.

Anualmente, realizam-se os tratos culturais de controle de plantas espontâneas, coroamento, adubação mineral e podas nos cupuaçuzeiros cultivados no sistema agroflorestal experimental em Cantá, Roraima. Para nutrição das plantas, aplica-se 250 g de ureia (45\% de N), 650 g de superfosfato simples (18\% de $\mathrm{P}_{2} \mathrm{O}_{5}, 16 \%$ de Ca e $8 \%$ de S), 300 g de cloreto de potássio (60\% de $\mathrm{K}_{2} \mathrm{O}$ ) e 50 g de FTE BR 12 (3,9\% de $\mathrm{S}, 1,8 \%$ de $\mathrm{B}_{2} \mathrm{O}_{3}$, 0,85 g de $\mathrm{CuO}, 3,0 \%$ de $\mathrm{Fe}_{2} \mathrm{O}_{3}, 2,0 \%$ de $\mathrm{MnO}_{2}, 0,10 \%$ de $\mathrm{MoO}_{3}$ e 9,0\% de $\mathrm{ZnO}$ ) em cada planta, distribuindo os adubos em sucos a 1,5 m das linhas de cupuaçuzeiros. As plantas de cupuaçuzeiro são submetidas às podas para condução do crescimento vegetativo e a retirada dos órgãos injuriados por insetos e/ou doenças, que é uma recomendação técnica para manter a qualidade fitossanitária no cultivo em escala comercial (Souza et al., 1999; Benchimol, 2004).

Em outubro de 2016, 60 ramos plagiotrópicos (secundários, terciários e quaternários) de cupuaçuzeiro, distribuídos em 30 plantas do pomar (2 ramos por planta), com botões florais, flores e frutos em estágio inicial de desenvolvimento (diâmetro máximo de $2 \mathrm{~cm}$ ), foram marcados com fita colorida, evitando-se ramos primários e pequenos, marcando-se ramos em até $60 \mathrm{~cm}$ da "ponteira do ramo". A tomada de dados no campo foi feita, em média, a cada 15 dias, totalizando treze leituras, seguindo o seguinte cronograma: 03/10/2016 (1. $),$ 24/10/2016 (2. $\left.{ }^{a}\right), 14 / 11 / 2016$ (3. $\left.{ }^{a}\right), 05 / 12 / 2016$ (4. $\left.{ }^{a}\right), 19 / 12 / 2016$ (5. $\left.{ }^{a}\right)$, 04/01/2017 (6. $\left.{ }^{a}\right), 16 / 01 / 2017$ (7.a), 30/01/2017 (8. a), 13/02/2017 (9. $\left.{ }^{a}\right)$, 27/02/2017 (10. $\left.{ }^{a}\right)$, 16/03/2017 (11. $\left.{ }^{a}\right), 27 / 03 / 2017\left(12 .^{a}\right)$ e 14/04/2017 (13. $\left.{ }^{a}\right)$.

Baseando-se nos trabalhos desenvolvidos por Falcão; Lleras (1983), Calzavara; Mûller; Kahwage (1984), Barrera et al. (2006), Hernández et al. (2006; 2010) e Hernández; Hernández (2012), variáveis foram adaptadas para avaliação quantitativa dos frutos de cupuaçuzeiro, em condições de campo. As variáveis avaliadas nos ramos marcados, durante 
o período, foram: número de botões florais (NBF), número de flores e/ou resquícios florais (NFL), número de frutos total (NF), porcentagem de frutos viáveis (FV), porcentagem de frutos com presença de insetos (FPI), porcentagem de frutos rachados (FR), porcentagem de frutos com deformação e/ou mumificação (FDM), porcentagem de frutos com presença de fungos (FPF), diâmetro polar do fruto (DPF) e diâmetro equatorial do fruto (DEF). Utilizou-se paquímetro digital com valores expressos em milímetros (mm) para avaliar o DPF e o DEF.

Para monitorar as condições ambientais do experimento utilizou-se termômetro e higrômetro digital, com valores expressos em graus Celsius $\left({ }^{\circ} \mathrm{C}\right)$ e porcentagem (\%) de umidade relativa, respectivamente. Durante as avaliações (visitas), os parâmetros de umidade relativa do ar, temperatura do ar (altura de 1,5 m) e temperatura do solo (5 cm de profundidade), foram aferidos em três pontos diferentes da área do experimento, geralmente às 9 horas da manhã. Na área experimental, o índice pluviométrico acumulado foi calculado utilizando-se um pluviômetro analógico, o qual era verificado diariamente e os dados registrados por funcionários da Embrapa Roraima.

O delineamento experimental utilizado foi inteiramente casualizado para caracterização de DPF e DEF. O número de repetições variou de acordo com o número de frutos viáveis presentes nos ramos avaliados. Nas avaliações de DPF e DEF aos 0, 15, 30, 45, 60, 75, 90, 105, 120, 135, 150, 165 e 180 dias, o tamanho da amostra foi de 4, 42, 78, 78, 127, 79, 68, 58, 41, 35, 25, 12 e 5 repetições (frutos), respectivamente. Os dados foram submetidos ao teste de normalidade e foram validados estatisticamente por meio de análise de variância e regressão $(\mathrm{p}<0,05)$. As médias foram comparadas utilizando-se erro-padrão da média.

Para análise de regressão de DPF e DEF utilizou-se modelo logístico com três parâmetros, baseado nos valores de quadrado médio dos resíduos (Q.M.R) e coeficiente de determinação $\left(\mathrm{R}^{2}\right)$, sugestão da literatura para a cultura do cupuaçuzeiro (Barrera et al., 2006; Hernández et al., 2006; Hernandez et al., 2010; Hernández; Hernández, 2012). Os dados foram tabulados em planilha digital. As análises estatísticas foram realizadas 
utilizando-se o software Statistix 10.0 (Analytical Software, 2008). A plotagem das figuras foi realizada utilizando-se o software SigmaPlot 12.0 (Systat Software Inc., 2012).

\section{RESULTADOS E DISCUSSÃO}

A média de temperatura do ar, temperatura do solo e umidade relativa do ar durante 0 experimento foi de $31,4 \pm 0,6{ }^{\circ} \mathrm{C}, 29,2 \pm 0,6{ }^{\circ} \mathrm{C}$ e $59,9 \pm 5,2 \%$, respectivamente. Nota-se que houve maior amplitude térmica nas aferições realizadas no ar (1,5 m de altura do solo) do que nas realizadas no solo ( $0-5 \mathrm{~cm}$ de profundidade), uma vez que, as temperaturas do ar variaram entre $30,6 \pm 0,1$ e $32,3 \pm 0,1^{\circ} \mathrm{C}$ e as temperaturas do solo variaram entre $28,8 \pm 0,1 \mathrm{e}$ $29,8 \pm 0,1^{\circ} \mathrm{C}$. A umidade relativa do ar mínima (1,5 $\mathrm{m}$ de altura do solo) registrada durante as visitas ao experimento foi de $52,1 \pm 0,2 \%$, enquanto o ponto máximo registrado dentro do SAF com cupuaçuzeiros foi de $69,7 \pm 0,2 \%$. Registrou-se um total de $885 \mathrm{~mm}$ de chuva acumulada durante a safra 2016/2017 (outubro de 2016 a abril de 2017).

A floração do cupuaçuzeiro no Campo Experimental Confiança da Embrapa Roraima, município de Cantá, Roraima, Amazônia brasileira iniciou-se em outubro de 2016, coincidindo com a estação seca. O ápice desse evento ocorreu no mês de novembro, quando também foi observada a frutificação inicial, com o pico no mês de dezembro. O período de desenvolvimento do cupuaçu compreendeu 180 dias e foi considerado a partir da abertura da flor (antese), até a abscisão do fruto. Os picos de floração e frutificação assemelharam-se aos encontrados em regiões de clima Afi, conforme os registros de Calzavara; Mûller; Kahwage (1984) em Belém e de Venturieri (2011) em Marituba, ambas no Estado do Pará. 
Na primeira avaliação (dia 0), registrou-se um total de 545 botões florais (Figura 1), com média de nove botões florais por ramo, havendo alguns ramos com até 17 botões florais (60 cm de ramo), número bem superior ao relatado na literatura. Houve um decréscimo expressivo de NBF a partir do $15 .^{\circ}$ dia de desenvolvimento do fruto, até o $300^{\circ} \mathrm{e}$ 45. ${ }^{\circ}$ dia de monitoramento, com redução, em relação à primeira aferição, de 27,7\%, 82,4\% e 93,3\%, respectivamente. A partir do $120 .^{\circ}$ dia de avaliação não foram mais encontrados botões florais nos ramos selecionados. Porém, observou-se que em algumas árvores com histórico de ataque de vassoura-de-bruxa, mesmo após o final do estádio de brotação, novas estruturas reprodutivas (botões florais e flores) apareciam em ramos infectados pela doença.

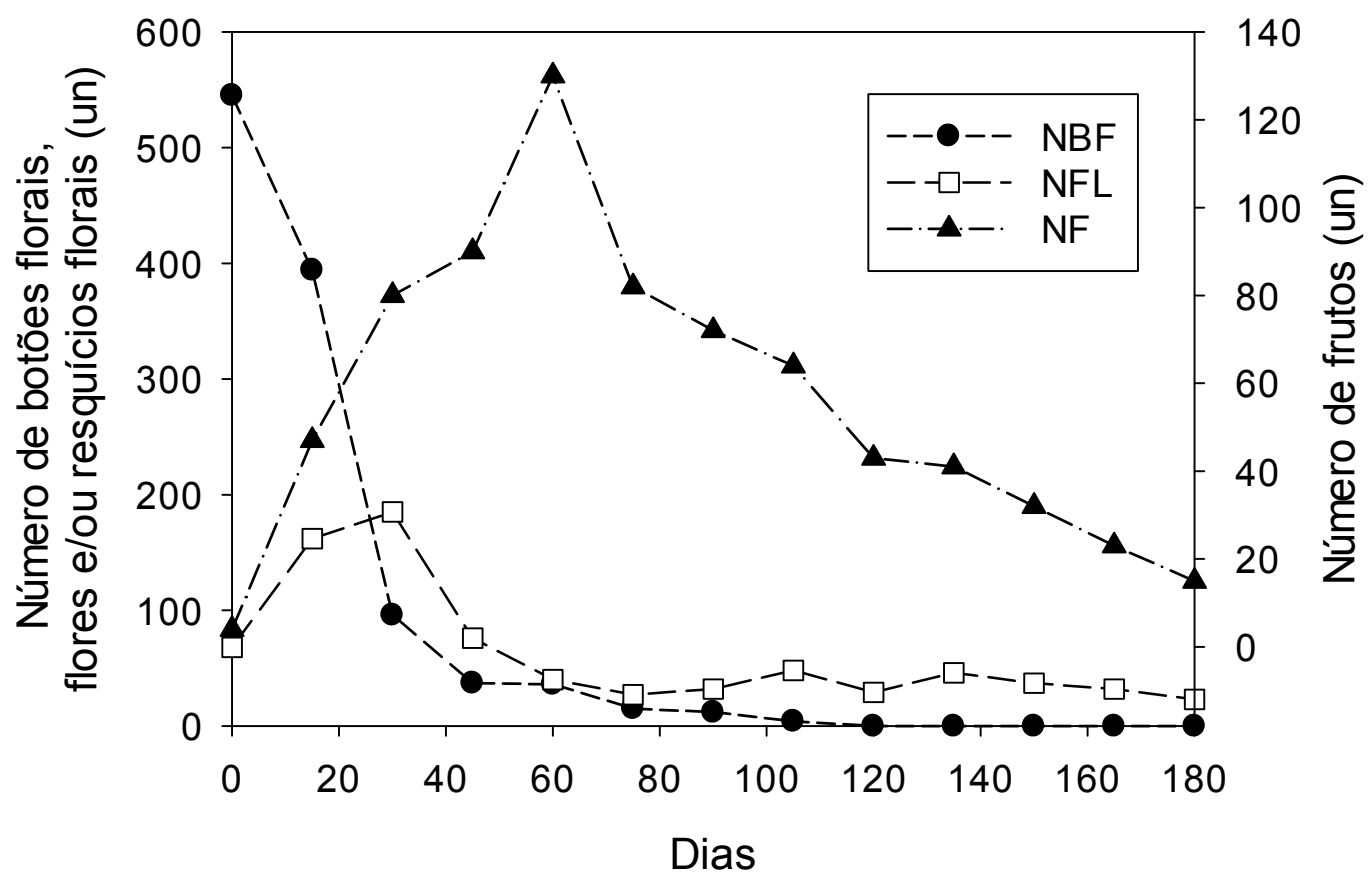

Figura 1. Valores totais de número de botões florais (NBF), número de flores e/ou resquícios florais (NFL) e número de frutos total (NF) avaliados durante o crescimento e maturação de frutos de cupuaçu cultivados em sistema agroflorestal no Campo Experimental Confiança, no município de Cantá, Roraima, Brasil. 
Foram necessários, aproximadamente, 30 dias da contagem de maior NBF para o ápice de NFL registrados. Dos 545 botões florais registrados obteve-se no máximo 180 flores e/ou resquícios florais (33,0\%) no 30. dia de monitoramento. Aos 45 dias observouse uma redução acentuada no NFL (58,9\%). Registrou-se o máximo de 6 flores por ramo dos cupuaçuzeiros. Na média geral, os ramos de cupuaçuzeiro têm 1,1 flores, mas deve-se deixar observado que, aos 15 e 30 dias de monitoramento, momento do evento fenológico de floração, o NFL por ramo chegou à média de até 2,5 e 2,9 flores, respectivamente.

O registro da maior quantidade de NF (130 frutos) foi realizado no $60 .^{\circ}$ dia de monitoramento (Figura 1), o que representa $70,3 \%$ do número máximo de flores e/ou resquícios florais registrados. Porém, apenas 6 frutos tornaram-se maduros e aptos para o consumo, o que representa uma relação de 30 flores para 1 fruto, ou até mesmo, 90 botões florais para 1 fruto. Comumente para essa espécie, a baixa polinização pode ser devido à pequena eficiência dos mecanismos de polinização e, dependentes da estrutura biológica da flora e dos agentes de transmissão de pólen (Acevedo; Cruz; Herrera, 2009). A maioria dos frutos avaliados durante o experimento foi considerada viável, com potencial para completar o desenvolvimento e a maturação fisiológica (Figura 2). 


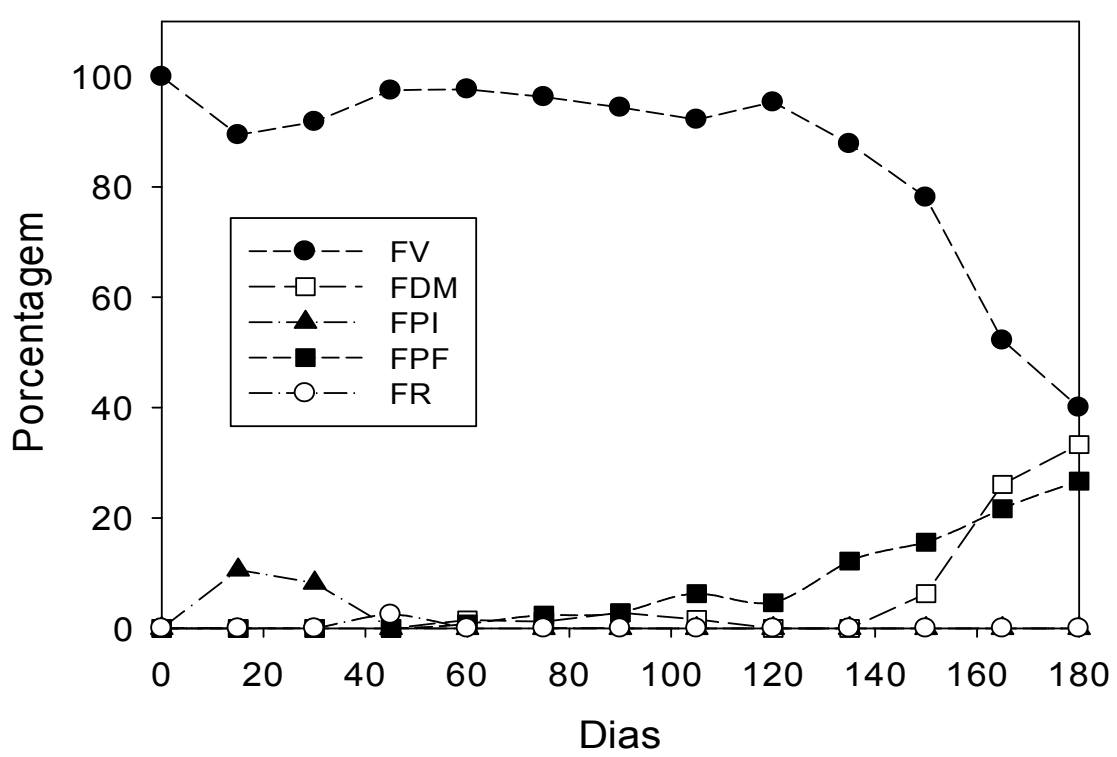

Figura 2. Porcentagens de frutos de cupuaçu viáveis (FV), deformados e/ou mumificados (FDM), com presença de insetos (FPI), com presença de fungos (FPF) e rachados (FR) durante crescimento e maturação de frutos de cupuaçu cultivados em sistema agroflorestal no Campo Experimental Confiança, no município de Cantá, Roraima, Brasil.

Os frutos de cupuaçuzeiros viáveis não apresentavam deformações, estruturas fúngicas, rachaduras e presença de insetos pragas, que apareceram nas plantas avaliadas nos primeiros dias de floração e desenvolvimento dos frutos. Há relatos na literatura que as formigas podem ser consideradas pragas para a cultura do cupuaçuzeiro (Falcão; Lleras, 1983; Acevedo; Cruz; Herrera, 2009), porém, há registros destes agindo como polinizadores, consequentemente, sendo benéficos, uma vez que o cupuaçuzeiro tem problemas com autopolinização.

Silva (1976) e Falcão; Lleras (1983) registraram a presença de formigas Camponotus sp. e Cromatogaster durante os eventos fenológicos do cupuaçuzeiro, e destacaram que além de apresentar relações simbióticas com pulgões da família Membracideae, há suspeita que as formigas possam alimentar-se do indumento lanoso, ferrugíneo, que recobre o pedúnculo floral, parte externa dos botões florais, podendo chegar a prejudicar a produção, já que debilita os pedúnculos de tal maneira que leva o abortamento das flores. Alves; 
Filgueiras; Homma (2014) afirmam que as flores dos cupuaçuzeiros são visitadas por muitas espécies de insetos como abelhas e formigas que tem tornado difícil distinguir entre polinizadores, predadores e pilhadores de pólen.

Porém, um fato bastante comum no cultivo de cupuaçuzeiro é o aparecimento de frutos rachados, principalmente aqueles que iniciam o seu processo de desenvolvimento antes do período chuvoso. Esse sintoma é típico de problema fisiológico, característico de frutos que passam por um período de estresse hídrico, causando lignificação do epicarpo (Acevedo; Cruz; Herrera, 2009), podendo ser causado pelo excesso de água absorvida no decorrer das primeiras chuvas após período de estiagem prolongado (Souza et al., 1999), com posterior aparecimento de fungos na rachadura (Calzavara; Mûller; Kahwage, 1984).

Na safra estudada, a porcentagem de frutos rachados foi muito baixa, chegando ao máximo de 2,5\% (2 frutos) aos 45 dias de monitoramento. Acredita-se que os baixos valores de frutos rachados tenham relação com a quantidade adequada de chuva na região, na safra estudada, uma vez que, no ano de 2016, após intenso estresse hídrico (déficit), registrou-se alta porcentagem de frutos em desenvolvimento com rachaduras (Guimarães et al., 2016). A chuva acumulada registrada na safra 2015/2016 do cupuaçuzeiro foi de 600 mm, bem inferior aos registrados na safra 2016/2017 (885 mm), correspondente a um acréscimo de $47,5 \%$ da quantidade de chuva acumulada.

Aos 60 dias de monitoramento registrou-se o aparecimento de ramos secos (tecido necrosado; vassoura seca) e folhas retorcidas infectadas pela vassoura-de-bruxa, e de frutos com deformações e/ou mumificados e estruturas fúngicas visíveis, representando 1,5\% e 0,8\% (2 e 1 frutos) do número total de frutos avaliados no dia, respectivamente. Na última avaliação, aos 180 dias de monitoramento, quando a maioria dos frutos marcados já havia alcançado maturidade fisiológica e se desprendido da planta, a porcentagem de FDM e FPF nos frutos restantes foi de 33,3\% e 26,7\% (5 e 4 frutos), respectivamente. De acordo com Nunes et al. (2002) o início da epidemia da vassoura-de-bruxa do cupuaçuzeiro está geralmente associado ao período seco (floração e frutificação), enquanto a produção de basidiocarpos inicia-se com o período chuvoso. 
O diâmetro polar e o diâmetro equatorial dos frutos apresentaram curva de crescimento do tipo sigmoidal simples em função dos dias de monitoramento do crescimento e desenvolvimento dos frutos de cupuaçu (Figura 3). Na primeira avaliação

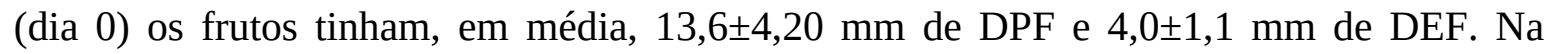
última avaliação, aos 180 dias de monitoramento, quando os frutos de cupuaçu

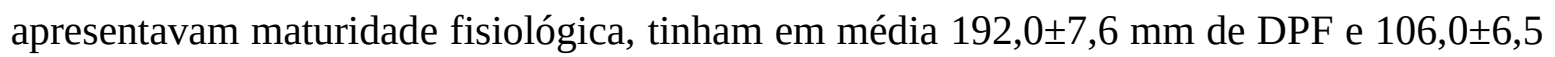
mm de DEF, o que representa um aumento de 1411,8 e $2650 \%$, respectivamente. Os valores de DPF e DEF aqui registrados assemelham-se aos apresentados por Acevedo; Cruz; Herrera (2009).

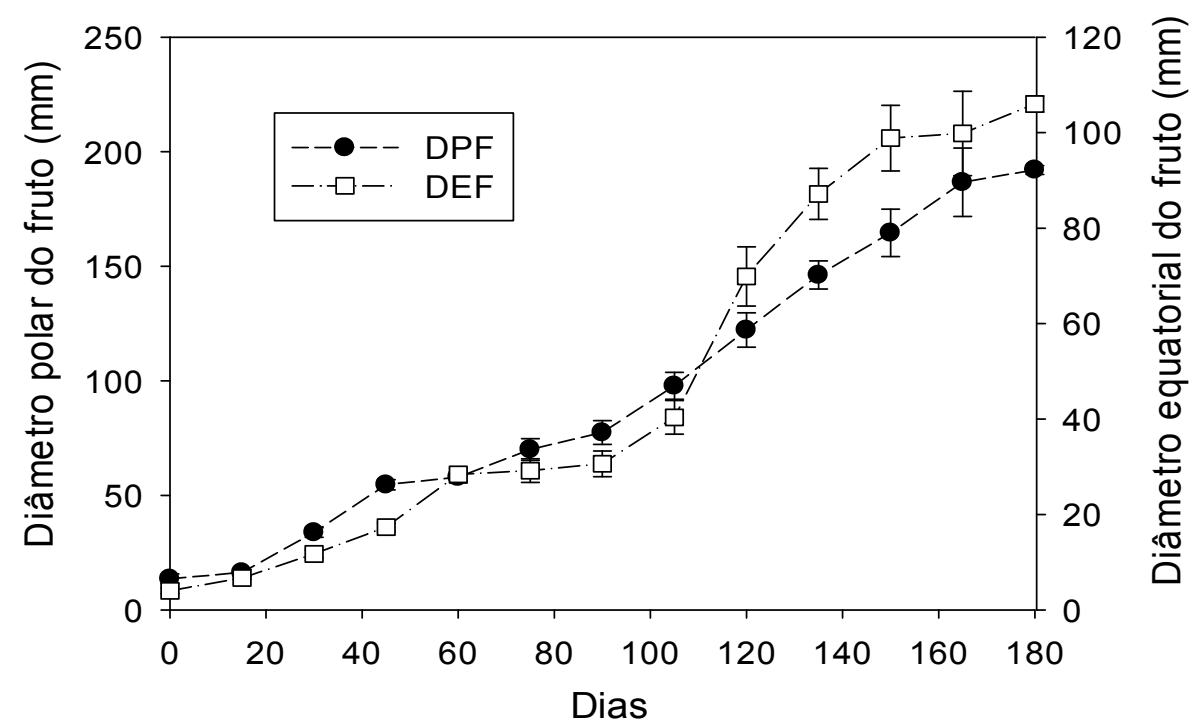

Figura 3. Diâmetro polar (DPF) e diâmetro equatorial (DEF) de frutos durante crescimento e maturação de frutos de cupuaçu cultivados em sistema agroflorestal no Campo Experimental Confiança, no município de Cantá, Roraima, Brasil.

O crescimento do fruto, que é um aumento irreversível de tamanho, é efetivado pela combinação de divisão e expansão celular (Raven; Evert; Eichhorn, 2014). Os frutos com maturidade fisiológica avaliados neste trabalho apresentaram formatos do tipo oblongo, elíptico e ovoide, com constrição basal variando de ligeiro a forte e ápice do fruto variando 
de agudo a redondo. Os modelos logísticos empregados para estimar DPF e DEF (Tabela 1) são semelhantes aos usados por Hernández et al. (2006), Hernandez et al. (2010) e Hernández; Hernández (2012).

Tabela 1. Modelos logísticos ajustados para os diâmetros polares e equatorial do fruto em função dos dias de desenvolvimento do fruto de cupuaçu em sistema agroflorestal no Campo Experimental Confiança, no município de Cantá, Roraima, Brasil

\begin{tabular}{cccc}
\hline Variável independente $\mathbf{Y}$ & Equação & $\boldsymbol{R}^{2}$ & Q.M.R. \\
\hline Diâmetro polar do fruto & $\mathrm{Y}=259,80 / 1+\mathrm{e}^{\left(2,6008-0,02080^{*} \mathrm{X}\right)}$ & 0,991 & 42,24 \\
Diâmetro equatorial do fruto & $\mathrm{Y}=126,65 / 1+\mathrm{e}^{(3,4920-0,0297 * \mathrm{X})}$ & 0,975 & 43,72 \\
\hline
\end{tabular}

$R^{2}=$ coeficiente de determinação; Q.M.R. = quadrado médio dos resíduos.

Hernández et al. (2006) afirmaram que durante o crescimento do fruto, intervalo de tempo que vai desde a antese a maturidade fisiológica, há um desenvolvimento ordenado de um grande número de tecidos vegetais, com a divisão celular terminada no momento da antese ou durante o começo do período de crescimento, e que o volume celular é o que representa maior contribuição para a expansão total do fruto. A mudança nos diâmetros é fundamentalmente produzida pela ação de fitohormônios como o ácido indolacético e as giberelinas, que em última instância se sintetizam por causa da fotossíntese e da respiração da planta.

\section{CONSIDERAÇÕES FINAIS}

O período de desenvolvimento do cupuaçu compreendeu 180 dias, considerando-se da abertura da flor (antese) até a abscisão do fruto. A floração e frutificação inicial deste fruto em sistema agroflorestal no Campo Experimental Confiança, no município de Cantá, Roraima, ocorreu nos meses de outubro e novembro, respectivamente, na safra 2016/2017.

Os diâmetros polar e equatorial dos frutos de cupuaçu apresentaram crescimento que se ajusta ao modelo sigmoidal simples. Na maturidade fisiológica estes frutos apresentaram 
formato do tipo oblongo, elíptico ou ovoide, com constrição basal variando de ligeiro a forte e ápice do fruto variando de agudo a redondo.

\section{AGRADECIMENTOS}

Ao apoio da Coordenação de Aperfeiçoamento de Pessoal de Nível Superior, a Empresa Brasileira de Pesquisa Agropecuária (Embrapa Roraima) e a Petrobras pelo patrocínio através do programa socioambiental (Projeto Cupuaçu Forte/nº 5850.0102917.16.2).

\section{REFERÊNCIAS}

ACEVEDO, C. J. E.; CRUZ, D. C.; HERRERA, W. Copoazú [Theobroma grandiflorum (Willd. Ex Spreng.) Schum.]: variabilidade y manejo del cultivo em el piedemonte amazônico. Caquetá - Colômbia: Corpoica, 2009. 40p.

ALBAGLI, S. Amazônia: fronteira geopolítica da biodiversidade. Parcerias estratégicas, n. 12, p. 5 - 19, 2001.

ALVES, R. M.; FILGUEIRAS, G. C.; HOMMA, A. K. O. Aspectos socioeconômicos do cupuaçuzeiro na Amazônia: do extrativismo a domesticação. In: SANTANA, A. C. (Ed.). Mercado, cadeias produtivas e desenvolvimento rural na Amazônia. $1^{\mathrm{a}}$ ed. Belém, PA: UFRA, 2014. p. 197-223.

AlViÁREZ, E. G.; MURILlO, W. A.; MURILlO, E. P.; ROJANO, B. A.; MÉNDEZ, J. J. A. Caracterización y extracción lipídica de las semillas del cacao amazónico (Theobroma grandiflorum). Ciencia en Desarrollo, Tunja, v. 7, n. 1, p. 103 - 109, 2016.

ANALYTICAL SOFTWARE. Statistix for Windows, version 9. 2008. Disponível em: https://www.statistix.com/free-trial/. Acesso em: dezembro de 2017.

BARRERA, J. A.; HERNÁNDEZ, M. S.; ÁVILA, G. V.; MARTÍNEZ, I. W.; MELGAREJO, L. M.; CASAS, A. E.; ZAMBRANO, J. E.; BEDOYA, C. D. Caracterizacion del crecimiento y desarrollo vegetativo de especies promisorias del genero Theobroma bajo condiciones de la amazonia colombiana. In: Oferta y potencialidades de um Banco de germoplasma del género Theobroma en el enriquecimiento de los sistemas productivos de la región Amazónica. MELGAREJO, L. M.; HERNANDÉZ, M. S.; J. A.; CARRILLO, M. Bogotá, Colombia: Instituto Amazónico de Investigaciones CientíficasSinchi, Universidad Nacional de Colombia, 2006, p. 65 - 106.

BENCHIMOL, R. L. Principais doenças do cupuaçuzeiro e recomendações de controle. Comunicado técnico nº 132. Embrapa Amazônia Oriental, Belém, Pará, 2004, 3 p. 
BUENO, G.; BACCARIN, J. G. Participação das principais frutas brasileiras no comércio internacional: 1997 a 2008. Revista Brasileira de Fruticultura, Jaboticabal, v. 34, n. 2, p. 424 - 434, 2012.

CALZAVARA, B. G., MILlER, C. H.; KAHWAGE, O. Fruticultura tropical: O cupuaçuzeiro, cultivo, beneficiamento e utilização do fruto. Embrapa; CPATU, Belém, Brasil, 1984, 104 p.

CORRÊA, E. F. Avaliação da decomposição e liberação de nutrientes da fitomassa de castanha-do-brasil (Bertholletia excelsa), cupuaçu (Theobroma grandiflorum) e gliricídia (Gliricidia sepium) em um sistema agroflorestal no estado de Roraima. 65 f. Dissertação (Mestrado em Agricultura e Sustentabilidade na Amazônia) - Universidade Federal do Amazonas, Manaus, 2005.

FALCÃO, M. de A.; LLERAS, E. Aspectos fenológicos, ecológicos e de produtividade do cupuaçu (Theobroma grandiflorum [Willd. Ex Spreng.] Schum.). Acta Amazonica, Manaus, v. 13, n. 6, p. 725 - 735, 1983.

FERREIRA, L. M. M.; TONINI, H. Comportamento da castanha-do-brasil (Bertholletia excelsa) e da cupiúba (Goupia glabra) em sistema agrosilvicultural na região da Confiança, Cantá - Roraima. Acta Amazonica, Manaus, v. 39, n. 4, p. 835 - 842, 2009.

GONDIM, T. M. de S.; THOMAZINI, M. J.; CAVALCANTE, M. de J. B.; SOUZA, J. M. L. de. Aspectos da produção de cupuaçu. Rio Branco: Embrapa Acre, 2001. 43p.

GUIMARÃES, P. V. P.; DURIGAN, M. F. B.; FONSECA, F. da S.; OLIVEIRA, R. L. C. de. Maturação de frutos de cupuaçu [Theobroma grandiflorum (Willd. ex Spreng.) Schum.] em sistema agroflorestal em Roraima. Anais do $2^{\circ}$ Seminário de Agroecologia da América do Sul, Dourados-MS, 2016.

HERNÁNDEZ, M. S.; BARRERA, J. A.; CARRILlO, M.; MARTINÉZ, O.; MELGAREJO, L. M.; GALVIS, J. A.; CASAS, A. E.; BOLAÑOS, C. Crecimiento y desarrollo de los frutos de especies promisorias del genero Theobroma, bajo condiciones de la Amazonia norte colombiana. In: Oferta y potencialidades de un banco de germoplasma del género Theobroma en el enriquecimiento de los sistemas productivos de la región Amazónica. MELGAREJO, L. M.; HERNANDÉZ, M. S.; J. A.; CARRILLO, M. Bogotá, Colombia: Instituto Amazónico de Investigaciones Científicas-Sinchi, Universidad Nacional de Colombia, 2006, p. 107 - 136.

HERNANDEZ, C.; CARRILLO, M. P.; BARRERA, J.; HERNÁNDEZ, M. S.; MARTÍNEZ, O.; FERNÁNDEZ-TRUJILLO, J. P. Physiological behavior and quality during growth of copoazú fruit. Proc. 6th International Postharvest Symposium. ISHS Acta Horticulturae, p. 877, 2010.

HERNÁNDEZ, C. L.; HERNÁNDEZ, M. S. G. Growth and development of the cupuaçu fruit [Theobroma grandiflorum (Willd. ex Spreng.) Schum.] in the western colombian Amazon. Agronomía Colombiana, Bogotá, v. 30, n. 1, p. 95 - 102, 2012. 
HULME, A.C. The Biochemistry of fruits and their products. London: Academic Press, 1970. 618p.

MACIEL, H. L.; ASSIS, D. S. de; YOKOMIZO, G. K. Arranjos agroflorestais no contexto da agroecologia: O caso dos agricultores da região do Médio Maracá no município do Mazagão, Amapá. Revista Verde de Agroecologia e Desenvolvimento Sustentável, Pombal, v. 10, n. 2, p. 271 - 277, 2015.

MOURÃO JUNIOR, M.; XAUD, M. R.; XAUD, H. A. M.; MOURA NETO, M. A. de; ARCO-VERDE, M.F.; PEREIRA, P. R. V. S.; TONINI, H. Precipitação pluviométrica em áreas de transição savana-mata de Roraima: campos experimentais Serra da Prata e Confiança. Comunicado Técnico n. 17. Embrapa Roraima. Boa Vista, Roraima. 2003. 7p.

NUNES, A. M. L.; BERGAMIN FILHO, A.; AMORIM, L.; NUNES, M. A. L.; DIAS, C. T. S. Análise da curva de progresso temporal da vassoura-de-bruxa do cupuaçuzeiro. Fitopatologia Brasileira, Brasília, v. 27, n. 4, p. 344 - 348, 2002.

RAVEN, P. H.; EVERT, R. F.; EICHHORN, S. E. Biologia vegetal. 8. ed. Rio de Janeiro: Guanabara Koogan, 2014. 850p.

SILVA, M. F. da. Insetos que visitam o "Cupuaçu", Theobroma grandiflorum (Willd. ex Spreng.) Schum. (Sterculiaceae) e índice de ataque nas folhas. Acta Amazonica, Manaus, v. 6, n. 1, p. 49 - 54, 1976.

SYSTAT SOFTWARE Inc. - SSI. SigmaPlot for Windows, version 12. 2012. Disponível em: http://www.sigmaplot.co.uk/products/sigmaplot/sigmaplot-details.php. Acesso em: dezembro de 2017.

SOUZA, A. das G. de; SILVA, S. E. L. da; TAVARES, A. M.; RODRIGUES, M. do R. L. A cultura do cupuaçu [Theobroma grandiflorum (Willd. ex Spreng.) Schum.]. Manaus: Embrapa Amazônia Ocidental, 1999. 39p.

SOUZA, A. das G. C. de; SOUZA, M. G.; PAMPLONA, A. M. S. R.; WOLFF, A. C. da S. Boas práticas na colheita e Pós-colheita do cupuaçu. Circular técnica $n^{0} 36$, Manaus-AM, 2011, 8 p.

VENTURIERI, G. A. Flowering levels, harvest season and yields of cupuassu (Theobroma grandiflorum). Acta Amazonica, Manaus, v. 41, n. 1, p. 143 - 152, 2011.

YANG, H.; PROTIVA, P.; CUI, B.; MA, C.; BAGGETT, S.; HEQUET, V; MORI, S.; WEINSTEIN, I. B.; KENNELLY, E. J. New bioactive polyphenols from Theobroma grandiflorum (“Cupuaçu”). Journal of Natural Products, Washington, v. 66, n. 11, p. 1501 1504, 2003. 